Pesq. Vet. Bras. 31(3):206-212, março 2011

\title{
Urolitíase: estudo comparativo em bovinos Guzerá oriundos de propriedades com e sem o problema ${ }^{1}$
}

\author{
Soraya Regina Sacco ${ }^{2 *}$ e Raimundo Souza Lopes²
}

\begin{abstract}
Sacco S.R. \& Lopes R.S. 2011. [Urolithiasis: A comparative study in Guzerá cattle from properties with and without the problem.] Urolitíase: estudo comparativo em bovinos Guzerá oriundos de propriedades com e sem o problema. Pesquisa Veterinária Brasileira 31(3):206-212. Departamento de Clínica Veterinária. Faculdade de Medicina Veterinária e Zootecnia, Universidade Estadual Paulista, Distrito de Rubião Júnior, Cx. Postal 560, Botucatu, SP 18618-000, Brazil. E-mail: soraya_sacco@ rocketmail.com

Many factors can contribute to the formation of urinary calculi, amongst these, the nutritional imbalances and the hardness of the water consumed by ruminants. The objective of this study was to identify the characteristics of properties which predispose to urolithiasis, through the evaluation in rural properties of the water, diet, and serum and urinary determinations of calcium, phosphorus, magnesium, chlorides, sodium, potassium, calculation of the fractional electrolyte excretion (FE), and creatinine, total protein serum levels, albumin and globulins. Samples of blood and urine of bovines, Guzerá, reared semi intensively, distributed for two groups, the first one, called urolithiasis group (Gu), composed by animals with history, clinical signals and ultrasonography confirmation of urolithiasis; the second one: controlled group (Gc), without history, nor signs of the illness. The bovines of the urolithiasis group consumed water with total hardness in the concentration of $166.0 \mathrm{mg} \mathrm{CaCO} 3 /$ $\mathrm{L}$. The diet of the animals of the Gu presented greater phosphorus concentration and inadequate $\mathrm{Ca}: \mathrm{P}$ relation. The levels of serum and urinary phosphorus of the animals of the Gu were higher of the Gc, as well as the serum magnesium concentration $(p<0,05)$. The creatinine concentrations didn't have an increase in the urolithiasis group, but occurred hypoproteinemia for hypoglobulinemia in the Gu $(p<0,05)$. The FEs of calcium, phosphorus and sodium had not differed between the groups ( $>0,05)$, but had significant reduction in the FEs of magnesium, chlorides and potassium of the urolithiasis group $(p<0.05)$. The union of these factors contributed for urolithiasis occurrence, being the total hardness of the water and the high phosphorus diet concentration the major factors in genesis of the calculations in bovines.

INDEX TERMS: Calculi, calcium, phosphorus, magnesium, urolithiasis, cattle.
\end{abstract}

RESUMO.- Diversos fatores podem contribuir para a formação de cálculos urinários, dentre estes, o desequilíbrio nutricional e a dureza da água consumida pelos ruminantes. O objetivo deste estudo foi identificar as características de propriedades que predispõem à urolitíase, através da avaliação da água, da dieta e determinações séricas e urinárias de cálcio, fósforo, magnésio, cloretos, sódio, potássio, cálculo da excreção fracionada (EF) dos eletróli-

\footnotetext{
${ }^{1}$ Recebido em 7 de janeiro de 2010.

Aceito para publicação em 24 de setembro de 2010.

2 Departamento de Clínica Veterinária, Faculdade de Medicina Veterinária e Zootecnia (FMVZ), Universidade Estadual Paulista (Unesp), Distrito de Rubião Júnior, Cx. Postal: 560, Botucatu, SP 18618-000, Brasil. *Autor para correspondência: soraya_sacco@rocketmail.com
}

tos, e da creatinina, proteína total, albumina e globulinas séricas. Foram colhidas amostras de sangue e urina de bovinos, Guzerá, criados semi intensivamente, distribuídos por dois grupos. O primeiro denominado grupo urolitíase (Gu), composto de animais com histórico, sinais clínicos e confirmação ultrassonográfica que apresentavam urolitíase; o segundo: grupo controle (Gc), sem histórico, nem sintomas da doença. Os bovinos do grupo urolitíase consumiam água com dureza total na concentração de $166,0 \mathrm{mg} \mathrm{CaCO} / \mathrm{L}$. A dieta dos animais do Gu apresentava maior concentração de fósforo e relação $\mathrm{Ca}: \mathrm{P}$ inadequada. Os teores de fósforo sérico e urinário dos animais do Gu foram maiores do que os do Gc, assim como a concentração sérica de magnésio $(p<0,05)$. Não houve aumento nas concentrações de creatinina no grupo urolití- 
ase, mas ocorreu hipoproteinemia por hipoglobulinemia $(p<0,05)$. As EFs de cálcio, fósforo e sódio não diferiram entre os grupos $(p>0,05)$, mas houve diminuição significativa nas EFs de magnésio, cloretos e de potássio do grupo urolitíase $(p<0,05)$. A união destes fatores contribuiu para a ocorrência da urolitíase, sendo dureza total da água e a alta concentração de fósforo na dieta os principais fatores na gênese dos cálculos em bovinos.

TERMOS DE INDEXAÇÃO: Cálculos, cálcio, fósforo, magnésio, urolitíase, bovinos.

\section{INTRODUÇÃO}

A urolitíase pode ser definida como a formação de cálculos ou concreções de muco, proteínas e minerais no trato urinário (Angus 1990, Divers 1993, Garcia et al. 1996, Ross 2001). Acomete todos os ruminantes, ocorrendo em bovinos de corte criados tanto extensivamente como intensivamente, mas raramente constitui um problema nos bovinos leiteiros, excetuando-se os vitelos e os garrotes leiteiros (Rebhun 2000).

O urólito forma-se quando solutos urinários orgânicos ou inorgânicos se precipitam (Radostitis et al. 2002). Esta formação resulta da interação de numerosos fatores fisiológicos, nutricionais e de manejo (Belknap \& Pugh 2005).

Sabe-se que a formação dos cálculos é desencadeada principalmente, pelo desequilíbrio nutricional nos teores de fósforo, cálcio e magnésio, o que é comum em animais confinados, que muitas vezes recebem ração com inadequada formulação mineral. Entretanto, pode também ocorrer urólitos em animais a pasto, quando se alimentam de plantas com alto teor de oxalato ou sílica (Petersson et al. 1988).

A relação entre a proporção cálcio e fósforo da dieta, quando inadequada, tem sido relatada na formação dos cálculos urinários, e é considerada importante principalmente em animais alimentados com grande quantidade de concentrado (Packett et al. 1964, Crookshank et al. 1967, Sorensen 1980).

A mensuração das concentrações de íons urinários $(\mathrm{Ca}$, $\mathrm{P}, \mathrm{Na}, \mathrm{K}, \mathrm{Cl}$ ) pode fornecer dados ao balanço mineral por meio de quantificação da excreção desses elementos. Contudo, a simples dosagem da concentração dos eletrólitos urinários não pode ser corretamente interpretada, sem que o volume urinário produzido seja considerado (King 1994). Para isto os valores dos eletrólitos no soro e na urina, além da creatinina sérica e urinária devem ser obtidos para a realização do cálculo da excreção fracionada, devido às variações na absorção e excreção de água, que dificultam a interpretação pela grande diversidade na concentração de solutos na urina (Caple et al. 1982).

Outro aspecto a ser considerado é o papel da qualidade da água consumida (Agreste et al. 2001). A dureza da água depende de íons presentes, principalmente o cálcio e magnésio, íons expressos na forma de carbonato (Adad 1982). Vários autores tentaram correlacionar positivamente a dureza da água consumida com a incidência da urolitíase (Alves 1997, Agreste et al. 2001).
Os bovinos da raça Guzerá (Bos taurus indicus) têm demonstrado alta produtividade na pecuária de produção de carne e sua capacidade de ganho de peso é superior em condições de confinamento e de semi confinamento, 0 que por muitas vezes pode aumentar o risco de desenvolvimento de urolitíase.

Devido à diversidade de fatores envolvidos na formação dos urólitos, devem-se esclarecer alguns pontos ainda considerados obscuros neste processo. Apesar dos esforços dos pesquisadores durante anos, o fenômeno geral da urolitíase permanece como um enigma e uma meta para estudos futuros.

\section{MATERIAL E MÉTODOS}

Foram utilizados 39 bovinos, da raça Guzerá, criados em sistema semi intensivo, alimentados com ração e suplementação mineral comerciais, pasto de Brachiaria decumbens, e água ad libitum, distribuídos por dois grupos.

No primeiro deles, denominado grupo urolitíase $(\mathrm{Gu})$, os animais eram oriundos de propriedade rural com problemas com a enfermidade, localizada na região de Porangaba, Estado de São Paulo, onde foram selecionados dez fêmeas e dez machos, de faixa etária variando entre seis meses até dois anos de idade, com histórico, sinais clínicos da enfermidade, confirmados através da ultrassonografia, sem realização de tratamento.

No segundo grupo, denominado de controle (Gc), os animais eram originários de propriedade rural sem problemas com a enfermidade, sendo composto de dez fêmeas e nove machos, de idade semelhante aos animais do Gu, alocados em uma outra região (Pirajuí - SP), sem histórico, nem sintomas da doença, não apresentando cálculos verificados por ultrssonografia do trato urinário.

Foram colhidas amostras de água das duas propriedades em frascos apropriados e mantidos sob refrigeração até o momento do envio ao Laboratório de Química, do Instituto Biociências, da Universidade Estadual Paulista, campus de Botucatu, SP, para análise físico-química e organoléptica.

Foram colhidas também amostras de pasto e silagem, acondicionadas em sacos plásticos vedados e enviadas ao Laboratório de Nutrição Mineral de Plantas, da Universidade Estadual Paulista, Fazenda Experimental Lageado, campus de Botucatu, SP. Finalmente, foram anotadas as informações referentes à ração e suplementação mineral.

Após anti-sepsia, foram colhidos $10 \mathrm{~mL}$ de sangue da veia jugular dos animais de ambos os grupos, em tubos para coIheita de sangue a vácuo ${ }^{3}$, sem aditivo, após o procedimento os tubos foram centrifugados, durante cinco minutos a $2000 \mathrm{~g}$. E então, o soro foi separado em tubos da marca Eppendorf ${ }^{4}$, e congelado a $-20^{\circ} \mathrm{C}$. As amostras de urina foram colhidas em frascos estéreis por micção natural, em volume de aproximadamente $100 \mathrm{~mL}$.

Todas as dosagens bioquímicas no soro e na urina foram realizadas utilizando-se reagentes comerciais. Sendo que as dosagens de cálcio e fósforo da urina foram realizadas após acidificação das amostras, segundo técnica descrita por Fleming

\footnotetext{
${ }^{3}$ Vacuplast $\Theta$, Real Lab Produtos e Equipamentos para Laboratório, Avenida Portugal 357, Ribeirão Preto, SP.

${ }^{4}$ Eppendorf®, Eppendorf do Brasil Ltda., Rua Ferreira de Araújo 221 conj.15, São Paulo, SP.
} 
et al. (1991). A leitura das reações foi realizada por espectrofotometria ${ }^{5}$. Os teores de sódio e potássio urinário e sérico foram determinados por meio de espectrofotometria de chama ${ }^{6}$.

Os cálculos da excreção fracionada dos eletrólitos foram realizados após as dosagens dos mesmos no soro e na urina, além da determinação da creatinina sérica e urinária. Dessa forma, podemos comparar a depuração de algum eletrólito com o da creatinina endógena e determinar a excreção renal de um eletrólito, através da equação abaixo, sendo Eu a concentração urinária do eletrólito, Cru a concentração urinária da creatinina, a Es concentração sérica do eletrólito e Crs a concentração sérica da creatinina:

$$
\text { Excreção fracionada }(\%)=\underline{\text { Eu }} \times \underline{\text { Es }} \times 100
$$

Os cálculos urinários dos animais abatidos e necropsiados foram analisados fisicamente, sendo avaliados: dimensões, forma, cor, superfície e consistência; e quimicamente através de método colorimétrico/precipitação ${ }^{7}$.

\section{RESULTADOS E DISCUSSÃO}

Os bovinos do grupo urolitíase consumiam água com dureza total na concentração de $166,0 \mathrm{mg} \mathrm{CaCO}_{3} / \mathrm{L}$, sendo esta totalmente proveniente da dureza de carbonatos; com dureza de magnésio abaixo do limite de quantificação. 0 grupo controle consumia água na concentração de $12,0 \mathrm{mg}$ $\mathrm{CaCO}_{3} / \mathrm{L}$, sendo a dureza de carbonatos de $8,0 \mathrm{mg} \mathrm{CaCO} /$ $\mathrm{L}$ e a de magnésio de $3,4 \mathrm{mg} \mathrm{CaCO}_{3} / \mathrm{L}$. Churchill et al. (1980) e Gomes et al. (1987) sugerem que a água com elevada dureza influencia na formação e crescimento de urólitos em humanos. Sahinduran et al. (2007), concluíram em seu estudo com bovinos, em regiões da Turquia, que a dureza da água pode contribuir para a urolitíase.

A quantidade de fósforo ingerida na ração era de $10 \mathrm{~g} /$ $\mathrm{kg}$ de ração no grupo urolitíase, e de $4 \mathrm{~g} / \mathrm{kg}$ de ração no grupo controle. A suplementação mineral também era rica em fósforo no grupo urolitíase, sendo os teores de fósforo

\footnotetext{
5 Espectrofotômetro 432 Femto®, Femto Indústria e Comércio de Instrumentos Ltda., Rua Jaguarí 12, Bosque da Saúde, São Paulo, SP.

${ }^{6}$ Fotômetro de chama FC 280 Celm $\AA$, Companhia Equipadora de Equipamentos Modernos Ltda., Alameda Amazonas 764, Alphaville, Barueri, SP.

7 SEPAC®, SEPAC Medicina Laboratorial. Responsável: Edgar Garcez Júnior, Biomédico, CRBM 2587.
}

de 88,0 e 40,0g/kg, para Gu e Gc respectivamente. O pasto de Brachiaria do grupo urolitíase também apresentava maior quantidade de fósforo, sendo de $4,4 \mathrm{~g} / \mathrm{kg}$ no Gu e de $2,1 \mathrm{~g} / \mathrm{kg}$ no Gc. Somente a quantidade de P na silagem era menor no Gu, sendo de $0,9 \mathrm{~g} / \mathrm{kg}$, enquanto no Gc era de $1,4 \mathrm{~g} / \mathrm{kg}$ de silo.

Além disso, a relação Ca:P da pastagem de Brachiaria do grupo urolitíase foi de aproximadamente 1:1,5, enquanto a do grupo controle era de 2:1. A silagem apresentava relação Ca:P de 2:1 e 3:1 nos grupos Gu e Gc, respectivamente. Sendo assim, a dieta dos animais do grupo urolitíase apresentava maior concentração de fósforo e baixa relação Ca: $P$, quando comparada ao grupo controle, os animais ingeriram maior quantidade de fósforo na ração, na suplementação mineral e na pastagem.

Segundo Riet-Correa (2001), a alimentação rica em fósforo aumenta a fosfatemia e, consequentemente, a eliminação de fosfatos pela urina. As dietas com uma relação Ca:P de 2:1 a 3:1 dificilmente causam urolitíase; quando a relação Ca:P diminui, aumenta-se o risco de cálculos. $\mathrm{Na}$ alimentação por longos períodos com rações com relação de cálcio e fósforo de 1:1 a 1:0,5 faz-se frequente a formação de cálculos urinários. Portanto, a alta quantidade de fósforo ingerida pelos animais, assim como a baixa relação Ca:P encontrada na pastagem de Brachiaria consumida pelo Gu podem ter contribuído para o aparecimento dos cálculos urinários.

Dentre os diversos fatores relacionados à ocorrência de urolitíase em ruminantes existem aqueles relacionados ao desequilíbrio mineral e as anormalidades do metabolismo mineral (Crookshank et al. 1967). Não ocorreram diferenças significativas nos teores séricos de cálcio. Houve hiperfosfatemia no grupo urolitíase, e um discreto aumento do magnésio sérico do $\mathrm{Gu}$, sendo ambos estatisticamente significativos $(p<0,05)$. As médias dos valores de potássio e de cloretos não diferiram estatisticamente. Já as médias de sódio do grupo controle foram significativamente maiores $(p<0,05)$ que as dos animais da propriedade com ocorrência de urolitíase, conforme mostra o Quadro 1.

Os teores de fósforo sérico dos animais do Gu apresentavam-se maiores do que os do Gc, esta hiperfosfatemia pode ter contribuído para a formação das pedras no trato urinário, o que corrobora com Packett et al. (1968), que encontraram elevada concentração de $\mathrm{P}$ sérico em

Quadro 1. Médias, desvios padrão e coeficiente de variação (CV) para cálcio, fósforo, magnésio, sódio, potássio e cloretos no soro dos animais do grupo urolitíase e do grupo controle

\begin{tabular}{ccccccc}
\hline Grupos & $\begin{array}{c}\text { Cálcio(Ca) } \\
(\mathrm{mg} / \mathrm{dL})\end{array}$ & $\begin{array}{c}\text { Fósforo(P) } \\
(\mathrm{mg} / \mathrm{dL})\end{array}$ & $\begin{array}{c}\text { Magnésio(Mg) } \\
(\mathrm{mg} / \mathrm{dL})\end{array}$ & $\begin{array}{c}\text { Sódio(Na) } \\
(\mathrm{mmol} / \mathrm{L})\end{array}$ & $\begin{array}{c}\text { Potássio(K) } \\
(\mathrm{mmol} / \mathrm{L})\end{array}$ & $\begin{array}{c}\text { Cloretos(Cl) } \\
(\mathrm{mmol} / \mathrm{L})\end{array}$ \\
\hline Urolitíase & $7,93 \pm 1,82$ & $7,64 \pm 0,78^{\mathrm{b}}$ & $2,31 \pm 0,31^{\mathrm{b}}$ & $134,50 \pm 30,79^{\mathrm{a}}$ & $5,93 \pm 2,26$ & $104,00 \pm 7,60$ \\
Controle & $8,79 \pm 1,62$ & $4,65 \pm 0,93^{\mathrm{a}}$ & $1,71 \pm 0,40^{\mathrm{a}}$ & $207,47 \pm 58,440^{\mathrm{b}}$ & $6,31 \pm 2,29$ & $104,09 \pm 6,98$ \\
CV $(\%)$ & 20,70 & 13,90 & 17,90 & 27,20 & 37,20 & 7,00 \\
Referências & $9,70-12,40^{\mathrm{c}}$ & $5,60-6,5^{\mathrm{c}}$ & $1,80-2,30^{\mathrm{c}}$ & $132,00-152,00^{\mathrm{c}}$ & $3,90-5,80^{\mathrm{c}}$ & $97,00^{-111,00^{\mathrm{c}}}$ \\
& $8,39^{\mathrm{d}}$ & $4,50^{\mathrm{d}}$ & $2,68^{\mathrm{d}}$ & & $4,49^{\mathrm{d}}$ & $93,32^{\mathrm{d}}$ \\
\hline
\end{tabular}

a,b Médias seguidas de letras diferentes na coluna diferem-se estatisticamente $(p<0,05)$ pelo Teste de Tukey.

c Fonte: Radostits et al. (2002) e Kaneko et al. (2008).

d Fonte: Morais et al. (2000). 
Quadro 2. Médias, desvios padrão e coeficiente de variação (CV) para proteína total, albumina e globulinas séricas dos animais do grupo urolitíase e do grupo controle

\begin{tabular}{cccc}
\hline Grupos & $\begin{array}{c}\text { Proteína total } \\
(\mathrm{g} / \mathrm{dL})\end{array}$ & $\begin{array}{c}\text { Albumina } \\
\mathrm{I}(\mathrm{g} / \mathrm{dL})\end{array}$ & $\begin{array}{c}\text { Globulinas } \\
\mathrm{I}(\mathrm{g} / \mathrm{dL})\end{array}$ \\
\hline Urolitíase & $5,89 \pm 0,56^{\mathrm{a}}$ & $3,59 \pm 0,36$ & $2,29 \pm 0,73^{\mathrm{a}}$ \\
Controle & $6,71 \pm 0,89^{\mathrm{b}}$ & $3,41 \pm 0,86$ & $3,30 \pm 0,76^{\mathrm{b}}$ \\
CV $(\%)$ & 11,70 & 18,60 & 26,80 \\
Referências $^{\mathrm{c}}$ & $6,74-7,46$ & $3,03-3,55$ & $3,00-3,48$ \\
\hline
\end{tabular}

a,b Médias seguidas de letras diferentes na coluna diferem-se estatisticamente $(p<0,05)$ pelo Teste de Tukey.

c Fonte: Kaneko et al. (2008).

ovinos com urolitíase. Bushman et al. (1965), Crookshank et al. (1967) e Hoar et al. (1970) confirmaram a importância da concentração de fósforo na alimentação de pequenos ruminantes, provando que uma baixa relação $\mathrm{Ca}: \mathrm{P}$ na dieta resulta em hiperfosfatemia, o que contribui para a formação dos cálculos.

Os animais do grupo urolitíase apresentaram taxas de magnésio sérico significativamente maiores $(p<0,05)$ do que os do grupo controle, assim como os animais estudados por Packett \& Hauschild (1964) e Packett et al. (1968). Estes autores afirmam que a hipermagnesemia é um achado frequente no sangue de ovinos acometidos por urolitíase. Haag \& Palmer (1928) encontraram cálculos de fosfato em ratos recebendo ração com altos teores de magnésio e fósforo e baixas taxas de cálcio e apontaram o magnésio como um dos fatores nutricionais que contribuíram para a formação dos cálculos. Segundo Kunkel et al. (1953) as alterações no metabolismo de magnésio são fatores determinantes no desenvolvimento da urolitíase, embora também seja necessário um metabolismo anormal de fósforo.

Os teores séricos de cálcio do grupo urolitíase, embora não diferissem estatisticamente $(p>0,05)$ dos animais do Gc, estavam abaixo do valor de referência proposto por Radostits et al. (2002), Kaneko et al. (2008) e do que a média obtida por Morais et al. (2000). Packett et al. (1968) em seu experimento encontraram taxas de cálcio mais baixas em ovinos com urolitíase. Portanto, as menores con- centrações de Ca sérico podem ter contribuído para a formação dos urólitos.

A média do potássio no grupo urolitíase não diferiu estatisticamente $(p>0,05)$ do grupo controle. Para Robbins et al. (1965), a maior concentração de potássio na dieta tende a diminuir a incidência de cálculos, sendo utilizado em aditivos na alimentação de pequenos ruminantes, para a prevenção da urolitíase.

Os valores séricos de cloretos não diferiram estatisticamente $(p>0,05)$ entre os grupos estudados. No entanto, a concentração média do sódio no soro dos animais do Gu $(134,50 \mathrm{mg} / \mathrm{dL})$ é semelhante a encontrada por Petersson et al. (1988) quando estudaram bovinos portadores de urolitíase $(139,80 \mathrm{mg} / \mathrm{dL})$. Como este valor de sódio sérico apresentou-se significativamente menor $(p<0,05)$ do que no grupo constituído por bovinos saudáveis consideramos que esta alteração pode ter contribuído para a gênese dos cálculos, pois segundo Petersson et al. (1988) a maior ingestão de cloreto de sódio $(\mathrm{NaCl})$ leva ao aumento da ingestão de água, o que reduz a formação de urólitos, pois o sal tem um efeito inibitório na formação de cálculos.

Não houve aumento nas concentrações séricas de creatinina no grupo urolitíase, sendo os valores encontrados de $1,54 \pm 0,62 \mathrm{mg} / \mathrm{dL}$ para Gu, e de $1,43 \pm 0,32 \mathrm{mg} / \mathrm{dL}$ para e Gc. Isto nos permite afirmar que a função renal dos animais apresentava-se normal. Petersson et al. (1988), estudando bovinos, relataram não haver aumento na creatinina. Sugimoto et al. (1992) encontraram aumento da creatinina somente nos bovinos acometidos de urolitíase com obstrução do fluxo urinário (azotemia pós renal).

Ocorreram alterações estatisticamente significativas $(p<0,05)$ que caracterizam hipoproteinemia por hipoglobulinemia nos animais do Gu quando comparados ao Gc (Quadro 2). Segundo Divers (1993), Ortolani (1996), Silva (1997) e Thompson (2001), a urolitíase em ruminantes promove diminuição do apetite até anorexia. Sugimoto et al. (1992) relataram perda de apetite nos animais clinicamente acometidos, porém estes apresentavam valores de proteína total aumentado, provavelmente devido à desidratação.

A mediana dos valores de cálcio urinário não diferiu

Quadro 3. Medianas do cálcio, fósforo, magnésio, sódio, potássio e cloretos urinários dos animais do grupo urolitíase e do grupo controle

\begin{tabular}{ccccccc}
\hline Grupos & $\begin{array}{c}\text { Cálcio(Ca) } \\
(\mathrm{mg} / \mathrm{dL})\end{array}$ & $\begin{array}{c}\text { Fósforo(P) } \\
(\mathrm{mg} / \mathrm{dL})\end{array}$ & $\begin{array}{c}\text { Magnésio }(\mathrm{Mg}) \\
(\mathrm{mg} / \mathrm{dL})\end{array}$ & $\begin{array}{c}\text { Sódio(Na) } \\
(\mathrm{mmol} / \mathrm{L})\end{array}$ & $\begin{array}{c}\text { Potássio(K) } \\
(\mathrm{mmol} / \mathrm{L})\end{array}$ & $\begin{array}{c}\text { Cloretos }(\mathrm{Cl}) \\
(\mathrm{mmol} / \mathrm{L})\end{array}$ \\
\hline Urolitíase & 2,78 & $5,54^{\mathrm{b}}$ & 6,51 & $26,00^{\mathrm{a}}$ & 34,00 & $167,70^{\mathrm{a}}$ \\
Controle & 1,52 & $1,47^{\mathrm{a}}$ & 5,94 & $35,00^{\mathrm{b}}$ & 34,70 & $320,36^{\mathrm{b}}$ \\
Referências & $10,59 \pm 3,07^{\mathrm{c}}$ & $0,80 \pm 0,13^{\mathrm{c}}$ & $3,86^{\mathrm{e}}$ & $36,40 \pm 25,60^{\mathrm{g}}$ & $91,20 \pm 36,90^{\mathrm{g}}$ & $347,00^{\mathrm{h}}$ \\
& $12,11 \pm 9,38^{\mathrm{d}}$ & $2,76 \pm 2,79^{\mathrm{d}}$ & $7,56^{\mathrm{f}}$ & & & \\
& $2,26^{\mathrm{e}}$ & & & & &
\end{tabular}

\footnotetext{
a,b Medianas seguidas de letras diferentes na coluna diferem-se estatisticamente $(p<0,05)$.

c Fonte: Singh et al. (1983).

d Fonte: Balarin (1990).

e Fonte: Petersson et al. (1988) em bovinos recebendo 0,1\% de Mg na dieta.

${ }^{f}$ Fonte: Petersson et al. (1988) em bovinos recebendo 0,3\% de $\mathrm{Mg}$ na dieta.

9 Fonte: Kitamura \& Ortolani (2007).

h Fonte: Bushman et al. (1965).
} 
nos grupos estudados. Já as medianas dos valores de fósforo e magnésio na urina foram significativamente maiores no grupo urolitíase $(p<0,05)$. Não houve diferença significativa entre os grupos para as medianas de potássio na urina, porém os valores de sódio e cloretos urinários mostraram-se significativamente diminuídos na urina do grupo urolitíase $(\mathrm{p}<0,05)$ (Quadro 3).

Os teores de fósforo urinário do grupo urolitíase foram significativamente maiores $(p<0,05)$ do que os do $G c$, o que corrobora com os achados de Packett et al. (1968), que determinaram que ovinos com urolitíase excretam mais fósforo na urina. A hiperfosfatúria no Gu pode ter ocorrido, provavelmente, porque os bovinos acometidos de cálculos no trato urinário recebiam ração, sal mineral e pastagem de Brachiaria com maior concentração de fósforo. De acordo com Jensen \& Mackey (1979), dietas ricas em P aumentam o fosfato sérico, e consequentemente há um aumento da excreção urinária de fósforo, favorecendo a calculogênese.

As medianas de magnésio urinário não diferiram entre os grupos ( $p>0,05)$. Packett \& Hauschild (1964), estudando ovinos com urolitíase, encontraram um aumento significativo do fósforo e do magnésio séricos, porém sem diferença significativa nos teores de magnésio na urina.

Os valores de cálcio urinário não diferiram entre os grupos $(p>0,05)$, sendo semelhantes à média encontrada por Petersson et al. (1988) em bovinos recebendo $0,1 \%$ de $\mathrm{Mg}$ na dieta. Tiruneh (2006) estudando alterações bioquímicas na urina de bovinos oriundos de propriedade com histórico de urolitíase, observou que animais acometidos por urolitíase apresentavam baixa concentração urinária de cálcio.

A concentração urinária de potássio não diferiu estatisticamente $(p>0,05)$ nos grupos estudados, sendo menores que os valores encontrados por Kitamura \& Ortolani (2007).

Os valores urinários de sódio e cloretos encontraramse significativamente $(p<0,05)$ diminuídos no Gu. Bushman et al. (1968) encontraram valores semelhantes de cloretos urinários $(170,0 \mathrm{mmol} / \mathrm{kg})$ em ovinos de uma propriedade com prevalência de $50 \%$ dos animais com cálculos. Para os autores, uma maior concentração urinária de cloretos é um sinal favorável para prevenção dos urólitos.

Udall et al. (1965), estudando ovinos acometidos por cálculos, observaram que os cloretos urinários inibem a for- mação de cristais na urina. Cuddford (1978) acredita que os cloretos auxiliam na formação de compostos solúveis de sais de fosfato de magnésio e cálcio. Entretanto, Bushman et al. (1968) relataram que somente o aumento da excreção urinária de cloretos não protege contra a formação de urólitos, já que utilizando uma concentração de $4 \%$ de $\mathrm{NaCl}$ na dieta, conseguiram um maior teor urinário de cloretos, porém uma redução discreta na formação de cálculos.

A creatinina urinária do grupo urolitíase encontrava-se significativamente $(p<0,05)$ maior no grupo urolitíase $(55,62$ $\mathrm{mg} / \mathrm{dL})$ do que no grupo controle $(32,80 \mathrm{mg} / \mathrm{dL})$. No entanto, dentro dos valores de referência para bovinos saudáveis preconizados por Balarin (1990) (124,32 $\pm 71,99 \mathrm{mg} / \mathrm{dL})$.

Segundo Traver et al. (1976) e Caple et al. (1982) variações na absorção e excreção de água dificultam a interpretação dos valores de cálcio e fósforo na urina. Por este fator, foi determinada a excreção fracionada (EF) dos eletrólitos urinários.

As medianas da excreção fracionada de cálcio e fósforo não diferiram estatisticamente entre os grupos $(p>0,05)$, sendo semelhantes aos valores determinados por Balarin (1990) e por Lefebvre et al. (2008) em fêmeas bovinas não lactantes. Houve diminuição significativa na excreção fracionada de magnésio do grupo urolitíase (Quadro 4) $(p<0,05)$.

A mediana da excreção fracionada de magnésio foi significativamente menor no $\mathrm{Gu}(11,14 \%)$ do que no $\mathrm{Gc}$ $(20,20 \%)(p<0,05)$. Lefebvre et al. (2008) demonstraram que a excreção fracionada de $\mathrm{Mg}$ varia de 4,96 a $11,73 \%$ em fêmeas bovinas não lactantes, e de 18,5 a 21,5\% em vacas holandesas com diferentes concentrações de potássio na dieta.

Li (1985) e Asplin et al. (2000) afirmam que o magnésio é considerado como inibidor da cristalização, nucleação e crescimento de urólitos de oxalato de cálcio. Portanto, uma menor excreção fracionada de Mg pode indicar uma menor secreção deste eletrólito pelos túbulos renais, o que causaria uma maior predisposição aos cálculos urinários.

Não houve diferença estatística $(p>0,05)$ na excreção fracionada de sódio entre os grupos estudados. Mas houve diminuição significativa da excreção fracionada de cloretos e de potássio no grupo urolitíase $(p<0,05)$, estes íons, segundo Udall et al. (1965), ligam-se à mucoproteínas e diminuem a formação de cálculos, e por isso são

Quadro 4. Medianas da excreção fracionada de cálcio, fósforo, magnésio, sódio, potássio e cloretos dos animais do grupo urolitíase e do grupo controle

\begin{tabular}{ccccccc}
\hline Grupos & $\begin{array}{c}\text { Cálcio (Ca) } \\
(\%)\end{array}$ & $\begin{array}{c}\text { Fósforo (P) } \\
(\%)\end{array}$ & $\begin{array}{c}\text { Magnésio }(\mathrm{Mg}) \\
(\%)\end{array}$ & $\begin{array}{c}\text { Sódio (Na) } \\
(\%)\end{array}$ & $\begin{array}{c}\text { Potássio (K) } \\
(\%)\end{array}$ & $\begin{array}{c}\text { Cloreto }(\mathrm{Cl}) \\
(\%)\end{array}$ \\
\hline Urolitíase & 1,58 & 2,43 & $11,14^{\mathrm{a}}$ & 1,37 & $23,77^{\mathrm{a}}$ & $6,24^{\mathrm{a}}$ \\
Controle & 1,45 & 2,12 & $20,20^{\mathrm{b}}$ & 1,43 & $34,70^{\mathrm{b}}$ & $20,18^{\mathrm{b}}$ \\
Referências & $2,36 \pm 1,84^{\mathrm{c}}$ & $0,97 \% \pm 0,78^{\mathrm{c}}$ & $4,96-11,73^{\mathrm{d}}$ & $1,97 \pm 0,63^{\mathrm{f}}$ & $49,3 \pm 9,2^{\mathrm{f}}$ & $3,16 \pm 1,12^{\mathrm{f}}$ \\
& $0,17-4,44^{\mathrm{d}}$ & $1,30-29,9^{\mathrm{d}}$ & $18,5-21,5^{\mathrm{e}}$ & $1,30 \pm 0,13^{\mathrm{g}}$ & $55,16 \pm 4,12^{\mathrm{g}}$ & $2,12 \pm 0,11^{\mathrm{g}}$ \\
\hline
\end{tabular}

a,b Medianas seguidas de letras diferentes na coluna diferem-se estatisticamente $(p<0,05)$.

c Fonte: Balarin (1990).

d Fonte: Lefebvre et al. (2008) em fêmeas bovinas não lactantes.

e Fonte: Lefebvre et al. (2008) em diferentes concentrações de potássio na dieta de bovinos.

${ }^{f}$ Fonte: Neiger \& Hagemoser (1985).

g Fonte: Itoh (1998). 
utilizados com aditivos dietéticos na prevenção da urolitíase.

Para Carlson (2006), os valores de referência para EF dos eletrólitos têm grande amplitude, e as principais fontes destas variações são as diferenças na dieta e condições ambientais, ou experimentais. Este fato dificulta a interpretação comparativa das duas propriedades, já que os animais estudados vivem sob condições climáticas diferentes, e recebem diferentes tipos de alimentação.

A urina dos animais do Gu apresentava-se significativamente mais amarela e turva, com maior densidade urinária do que a do $G c(p<0,01)$. Isto devido à alta concentração de constituintes formadores, fazendo com que esta se tornasse supersaturada com cristais calculogênicos (Osorne et al. 2000).

Segundo Floyd (1993), o pH urinário alcalino facilita o processo de precipitação de cristais de carbonato de cálcio e de fosfatos, fazendo com que os colóides urinários percam sua capacidade de se comportar como um gel protetor. Os bovinos do grupo urolitíase e do grupo controle apresentaram $\mathrm{pH}$ alcalino urinário de 8,0 e 8,5, respectivamente.

A mediana da proteína urinária foi estatisticamente maior $(p<0,05)$ no grupo urolitíase $(100 \mathrm{mg} / \mathrm{dL})$, quando comparada com o controle $(30 \mathrm{mg} / \mathrm{dL})$. A proteinúria no grupo urolitíase, corrobora com os achados de Sugimoto et al. (1992), podendo ter origem pós-renal.

Os cálculos urinários obtidos de bovinos do grupo urolitíase eram constituídos principalmente por fosfato amoníaco magnesiano (fosfato triplo) e em menor proporção por oxalato de cálcio. Segundo Radostits et al. (2002) os cálculos que contêm carbonato de cálcio são mais comuns em ruminantes que se alimentam em pastagem com plantas ricas em oxalato. Oxalato de cálcio e fosfato amoníaco magnesiano são constituintes comuns de cálculos em ruminantes alimentados a pasto.

\section{CONCLUSÕES}

O resultado do presente estudo, nas condições em que foi realizado, nos permite concluir que a dureza de água consumida pelos animais caracteriza esta como uma das causas, que predispõem os bovinos à enfermidade. Além disso, a relação inadequada de $\mathrm{Ca}: \mathrm{P}$ da dieta consumida pelos animais pode predispor os bovinos ao surgimento dos cálculos urinários. $\mathrm{O}$ aumento da ingestão de fósforo causa hiperfosfatemia, e consequente aumento do fósforo urinário, que acompanhado de hipermagnesemia, contribuem para a gênese dos cálculos. As diminuições da excreção fracionada de cloretos e de potássio no grupo de animais com ocorrência de urolitíase indicam que estes íons são importantes na prevenção da urolitíase, já que se ligam a mucoproteínas, diminuindo a formação de urólitos.

\section{REFERÊNCIAS}

Adad J.M.T. 1982. Controle Químico de Qualidade. Guanabara Dois, Rio de Janeiro. p.23-25.

Agreste S.A., Schor N. \& Heilberg I.P. 2001. Atualização em nefrologia clínica: papel da constituição físico-química da água potável na litogênese renal. J. Bras. Nefrol. 23(1):45-48.
Alves J.A. 1997. Urolitíase experimental: efeitos da dureza total da água no crescimento de cálculos induzidos na bexiga de ratos Wistar. Dissertação de Mestrado em Saúde Coletiva, Universidade Federal do Mato Grosso, Cuiabá, MT. 57p.

Angus K.W. 1990. Nefropathy in young lambs. Vet. Rec. 126:525-528.

Asplin J.R., Murray J.F. \& Coe F.L. 2000. Nephrolithiasis, p.1774-1819. In: Brenner A. \& Rector S. (Eds), The Kidney. W.B Saunders, Philadelphia.

Balarin N.R.S. 1990. Avaliação do estado nutricional de cálcio e fósforo em bovinos por meio da análise bioquímica da urina. Dissertação de Mestrado em Clínica Veterinária, Universidade Estadual Paulista "Júlio de Mesquita Filho", Botucatu, SP. 34p.

Belknap E.B. \& Pugh D.G. 2005. Enfermidades do sistema urinário, p.287-310. In: Pugh D.G. (Ed.), Clínica de Ovinos e Caprinos. Roca, São Paulo.

Bushman D.H., Emerick R.J. \& Embry L.B. 1965. Experimentally induced ovine phosphatic urolithiasis: Relationship involving dietary calcium, phosphorus and magnesium. J. Nutr. 87:499-503.

Bushman D.H., Emerick R.J. \& Embry L.B. 1968. Effect of various chlorides and calcium carbonate on calcium, phosphorus, sodium, potassium and chloride balance and their relationship to urinary calculi in lambs. J. Am. Sci. 27:490-496.

Caple I.W., Bourket J.M. \& Ellist P.G. 1982. An examination of the calcium and phosphorus nutrition of throughbred racehorses. Aust. Vet. J. 58(4):132-135

Carlson G.P. 2006. Testes bioquímicos, p.427-448. In: Smith B.P. (Ed.), Medicina Interna de Grandes Animais. $3^{\underline{a}}$ ed. Manole, Barueri.

Churchill D.N., Maloney C.M. \& Bear J. 1980. Urolithiasis: A study of drinking water hardness and genetic factors. J. Chronic Dis. 33:727731.

Crookshank H.R., Robbins J.D. \& Kunkel H.O. 1967. Relationship of dietary mineral intake to serum mineral level and the incidence of urinary calculi in lambs. J. Anim. Sci. 26:1179-1185.

Cuddford D. 1978. Role of magnesium in the aetiology of ovine urolithiasis in fattening store lambs and intensively fattened lambs. Vet. Rec. 121:194-197.

Divers T.J. 1993. Moléstias do sistema renal, p.884-886. In: Smith B.P. (Ed.), Tratado de Medicina Interna de Grandes Animais: Moléstias de Eqüinos, Bovinos, Ovinos e Caprinos. Manole, São Paulo.

Fleming S.A., Hunt E.L., Riviere J.E. \& Anderson K.L. 1991. Renal "clearance" and fractional excretion of electrolytes over four 6-hour periods in cattle. Am. J. Vet. Res. 52(1):5-8.

Floyd J.G. 1993. Current Veterinary Therapy. 3. Food animal practice. W.B. Saunders, Philadelphia. 966p.

Garcia M., Della Libera A.M.M.P. \& Barros Filho I.R. 1996. Manual de Semiologia e Clínica de Ruminantes. Varela, São Paulo. 247p.

Gomes O.F., Flores S.L. \& Espinosa S.L. 1987. Panorama nacional de la litiasis de las vias urinárias y su relacion com el contenido de calcio y magnesio y el suelo de México. Mol. Col. Mex. Urol. 4:23-26.

Haag J.R. \& Palmer L.S. 1928. The effect of variations in the proportions of calcium, magnesium and phosphorus container in the diet. J. Biol. Chem. 76:367.

Hoar D.W., Emerick R.J. \& Embry L.B. 1970. Potassium, phosphorus and calcium interrelationship in influencing feedlot performance and phosphoric urolithiasis in lambs. J. Anim. Sci. 30:597-600.

Itoh N. 1998. Fractional electrolyte excretion in adult cows: Establishment of reference ranges and evaluation of seasonal variation. Vet. Clin. Pathol. 18(4):86-87.

Jensen R. \& Mackey D.R. 1979. Disease of feedlot cattle. W.B Saunders, Philadelphia. 1073p.

Kaneko J.J., Harvey J.W. \& Bruss M.L. 2008. Clinical Biochemistry of Domestic Animals. Academic Press, San Diego. 932p.

King C. 1994. Practical use of urinary fractionated excretion. J. Equine Vet. Sci. 14(9):464-468. 
Kitamura S.S. \& Ortolani E.L. 2007. Estudo de diferentes doses de furosemida sobre a função renal de bovinos hígidos. Ciência Rural 37(5):1349-1354.

Kunkel H.O., Burns K.H. \& Camp B.J. 1953. A study of sheep fed high levels of potassium bicarbonate with particular reference to induced hypomagnesemia. J. Anim. Sci. 12:451.

Lefebvre H.P., Dossin O., Trumel C. \& Braun J.P. 2008. Fractional excretion tests: A critical review of methods and applications in domestic animals. Vet. Clin. Pathol. 37(1):4-20.

Li M.K., Blacklok N.J. \& Garside J. 1985. Effects of magnesium on calcium oxalate crystallization. J. Urol. 133:123-125.

Morais M.G., Gonçalves L.C., Lopes H.O.S., Costa M.F.V. \& Nunes A.B. 2000. Variação sazonal de eletrólitos no sangue de vacas aneloradas sob pastejo contínuo de Brachiaria decumbens. Arq. Bras. Med. Vet. Zootec. 52(2):105-110.

Neiger R.D. \& Hagemoser W.A. 1985. Renal percent clearance ratios in cattle. Vet. Clin. Pathol. 14(1):31-35.

Ortolani E.L. 1996. Intoxicações e doenças metabólicas em ovinos: intoxicação cúprica, urolitíase e toxemia da prenhes, p.241-258. In: Silva Sobrinho A.G. (Ed.), Nutrição de Ovinos. Funep, Jaboticabal, SP.

Osborne C.A., Bartges J.W., Lulich J.P., Polzin D.J. \& Allen T.A. 2000. Canine urolithiasis, p.605-688. In: Hand M.S., Tatcher C.D., Remillard R.L. \& Roudebush P. (Eds), Small Animal Clinical Nutrition. $4^{\text {th }}$ ed. Mark Morris Institute, Missouri.

Packett L.V. \& Hauschild J.P. 1964. Mineral relationships in urolithiasis. J. Nutrition. 84:185.

Packett L.V., Linebergee R.O. \& Jackson H.D. 1968. Mineral studies in ovine phosphatic urolithiasis. J. Anim. Sci. 27:1716-1721.

Petersson K.H., Warner R.G., Kallfelz F.A. \& Crosetti C.F. 1988. Influence of magnesium, water, and sodium chloride on urolithiasis in veal calves. J. Dairy Sci. 71:3369-3377.

Radostits O.M., Gay C.C., Blood D.C. \& Hinchcliff K.W. 2002. Clínica Veterinária. 9aㅡ ed. Guanabara Koogan, Rio de Janeiro. $1737 p$.
Rebhun W.C. 2000. Doenças do trato urinário, p.435-453. In: Ibid. (Ed.), Doenças do Gado Leiteiro. Roca, São Paulo.

Riet-Correa F. 2001. Urolitíase em ruminantes, p.561-565. In: RietCorrea F., Schild A.L., Méndez M.C. \& Lemos R.A.A. (Eds), Doenças de Ruminantes e Eqüinos. Vol.2. 2 ${ }^{\mathrm{a}}$ ed. Varela, São Paulo.

Robbins J.D., Kunkel H.O. \& Crookshank H.R. 1965. Relationship of dietary mineral intake to urinary mineral excretion and the incidence of urinary calculi in lambs. J. Anim. Sci. 24:76-82.

Sahinduran S., Buyukoglu T., Gulay M.S. \& Tasci F. 2007. Increased water hardness and magnesium levels may increase occurrence of urolithiasis in cows from the Burdur region (Turkey). Vet. Res. Commun. 31:665-671.

Silva E.R. 1997. Urolitíase obstrutiva em pequenos ruminantes. Revta Bras. Med. Vet. 19(4):144-147.

Singh K., Gera K.L. \& Cahndna I.S. 1983. Biochemical constituents in the plasma and urine of normal and urolithiasis affected bovines. Indian Vet. J. 53(09):1016-1018.

Sorensen D.K. 1980. Urinary system, p.823-846. In: Amstutz H.E. (Ed.), Bovine Medicine and Surgery. $2^{\text {nd }}$ ed. American Veterinary Publications, California.

Sugimoto K., Sakurai N., Shirasaka H., Fujise Y., Shibata K., Shimoda K. \& Sakata J. 1992. Bovine cases of urolithiasis treated with traditional herbal medicine, P-3. J. Vet. Med. Sci. 53(3):579-582.

Thompson J.P. 2001. Urolitíase em ruminantes, p.948-950. In: Aiello S.E. (Ed.), Manual Merck de Veterinária. $8^{a}$ ed. Roca, São Paulo.

Tiruneh R. 2006. Ruminant urolithiasis in Ethiopia: Alterations of mineral concentrations in bovine urine and sheep sera according to the geographic origin or the diet regimen. Revue Méd. Vét. 157(5):261-264.

Traver D.S., Coffman J.R., Moore J.N., Salem C.A., Garner H.E., Johnson J.H. \& Tritschler L.G. 1976. Urine clearance ratios as a diagnostic aid in equine metabolism disease. Proc. Assoc. Equine Pract. 22:177-183.

Udall R.H., Seger C.L. \& Chow F.H.C. 1965. Studies on urolithiasis VI. The mechanism of action of sodium chloride in the control of urinary calculi. Cornell Vet. 55:198-203. 